\title{
Antegrade balloon dilatation of nasolacrimal duct obstruction in adults
}

\author{
A Kuchar, F J Steinkogler
}

\begin{abstract}
Aims-To determine the efficacy of antegrade balloon dilatation of postsaccal lacrimal stenosis in adults.

Methods-Balloon dilatation was performed in a series of 30 patients with complete nasolacrimal duct obstructions and epiphora. Obstruction was diagnosed by canalicular irrigation and transcanalicular endoscopic examination of the lacrimal pathway. Except for four cases in which general anaesthesia was applied, the procedure was performed under local anaesthesia. The Lacricath balloon catheter set was used. Silicone intubation was performed simultaneously. The time at which the tubes were removed depended on the findings at postoperative follow up but was, at the earliest, 3 months postoperatively.
\end{abstract}

Results-Success was objectified by irrigation and was evaluated subjectively at each follow up examination according to Munk's scale. In all cases the procedure could be performed with subsequent silicone intubation. Three months postoperatively $89.9 \%$ of all cases were positive on simple irrigation, and subjective success was also registered (Munk's grade 0 or 1 ). At 6 months $70 \%$ of all cases were positive on irrigation, again with subjective success (Munk's grade 0 or 1 ). One year postoperatively $73.3 \%$ of all procedures showed subjective success (two successful redilatations would raise the success rate to $79.9 \%$ ).

Conclusion-Retrograde as well as antegrade dilatation has been reported to be more or less successful in partial nasolacrimal obstruction. Although the procedure is used as primary treatment in cases of complete obstruction, it can still be performed under local anaesthesia on an outpatient basis. Long term observation will be required to prove the sustained effect of this procedure.

(Br f Ophthalmol 2001;85:200-204)

Ophthalmology,

University of Vienna,

Medical School,

Vienna, Austria

A Kuchar

F J Steinkogler

Correspondence to:

Dr A Kuchar, University Eye

Clinic Vienna, Waehringer

Guertel 18-20, A-1090

Vienna, Austria

andreas.kuchar@univie.ac.at

Accepted for publication

22 September 2000 scars, several procedures have been developed, including silicone intubation, ${ }^{3-5}$ endonasal laser
Postsaccal obstruction with consequent epiphora has been treated by procedures involving the creation of a new anastomosis between the lacrimal sac and the nose. Currently the most common surgical procedure is external dacryoassociated with a high success rate and with few side effects. ${ }^{12}$ In an attempt to dispense with general anaesthesia and to avoid external $\mathrm{DCR}^{6}{ }^{6}{ }^{7}$ and endocanalicular laser
procedures.

Lacrimal pathway dilatation is most frequently performed as retrograde dilatation, requiring radiographic and endonasal endoscopy, and is associated with a widely varying degree of success. ${ }^{13-22}$ Perry et al reported on antegrade dilatation in adult patients with partial nasolacrimal duct obstruction. ${ }^{23}$

In this study antegrade dilatation in complete postsaccal stenosis after endoscopy of the lacrimal system was performed. In all the cases reported here, a bypass procedure would have been performed in the past.

The efficacy of this new procedure is still to be determined.

Materials and methods

Between September 1998 and July 1999 balloon catheter dilatation was performed in a series of 30 patients with complete obstructed nasolacrimal systems. Traumatic cases, tough presaccal stenoses, and patients with a history of former lacrimal surgery were excluded from this new procedure. In six patients a bilateral procedure was performed. In order to avoid exceeding sample size over subjects only the first treated obstruction of these patients was included in the study. ${ }^{2425}$

Complete obstruction was confirmed by canalicular irrigation and proved by transcanalicular endoscopy.

Epiphora was evaluated subjectively according to a scale proposed by Munk and associates, which is graduated as follows: grade $0=$ no epiphora; grade $1=$ occasional epiphora requiring drying or dabbing less than twice a day; grade 2 = epiphora requiring dabbing two to four times per day; grade $3=$ epiphora requiring dabbing five to 10 times per day; grade $4=$ epiphora requiring dabbing more than 10 times per day; grade $5=$ constant tearing.

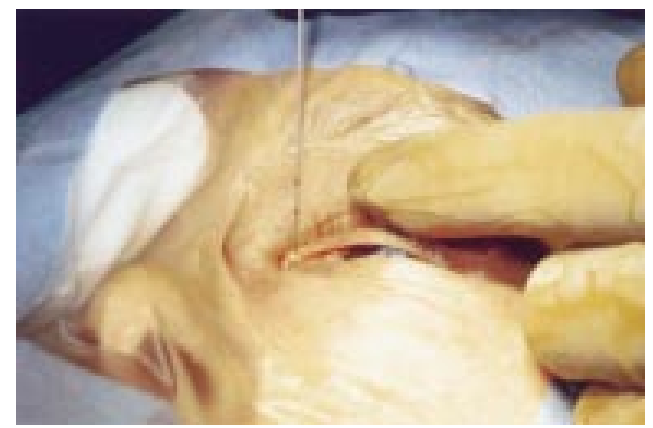

Figure 1 The Lacricath will be advanced until the upper mark has reached the superior punctum. This will be the most advanced position of the balloon. 


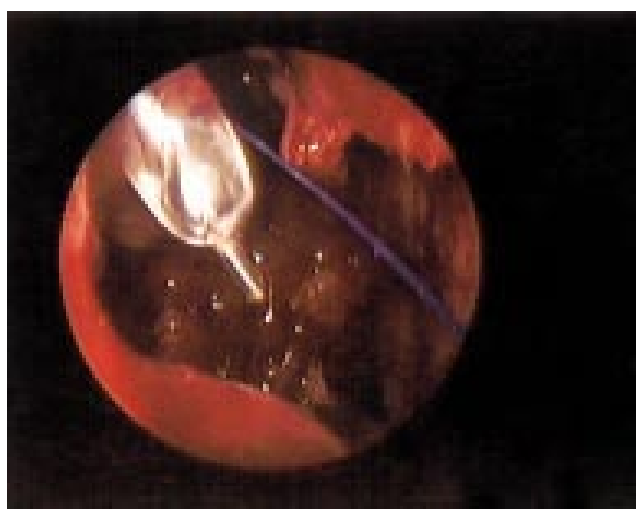

Figure 2 Inflated balloon catheter just reaching the nasal cavity, blue prolene thread behind the catheter.

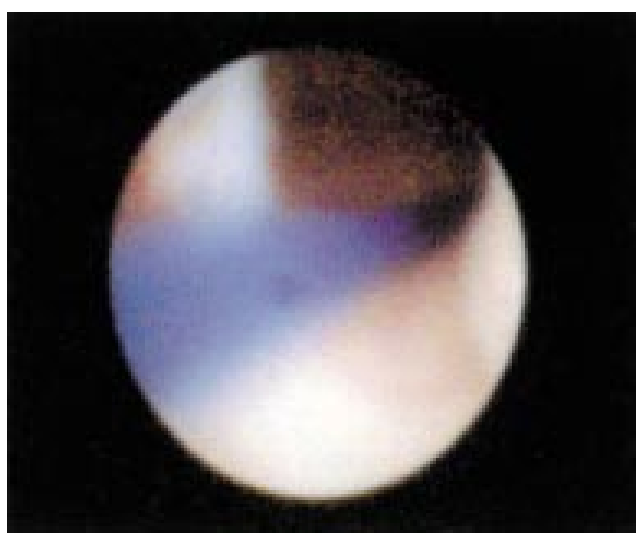

Figure 3 View from the lacrimal sac through the reopened nasolacrimal duct into the nose. Blue prolene thread passing through the nasolacrimal duct.

All patients suffered from at least grade 3 epiphora (Munk's classification). Nineteen female and 11 male patients were operated on by this new procedure after written consent had been obtained. The mean age of the patients was 55.8 (SD 14.7) years and the mean interval between the onset of epiphora and surgery was 14.4 (7.9) months. In four $(13.3 \%)$ cases a stenosis of the common canaliculus necessitated an additional Er:YAG laser membranotomy ${ }^{12}$ in conjunction with postsaccal dilatation. In these cases only a thin membranous membrane (less than $1 \mathrm{~mm}$ ) was present and could be opened by a few laser effects. After this procedure probing and syringing into the lacrimal sac was very easy.

Dilatation was performed under general anaesthesia in the first four cases. All other patients were operated on under local subcutaneous anaesthesia. Lignocaine (lidocaine) $2 \%$ was infiltrated into the medial canthus and the perisaccal area subcutaneously. The mucosa of the nose was anaesthetised with lignocaine spray.

The procedure was started with initial syringing and probing of the lacrimal system. Since all patients presented with complete postsaccal obstruction, probing up to the obstruction was started carefully; a mechanical opening of the obstruction either by means of high pressure syringing or mechanical pressure of the probe was performed until fluid reached the nasal cavity. In a next step the balloon catheter was introduced into the superior canaliculus and advanced into the lacrimal sac and further to the nasal cavity passing the area of the stenosis after reopening. The catheter was advanced up to the superior mark on the catheter just reaching the lacrimal punctum, meaning the most advanced position of the catheter (Fig 1). The balloon was inflated with a pressure of 9 bar for 90 seconds. Since the length of the catheter is about $3.0 \mathrm{~cm}$ the stenotic area was dilated by the balloon. In the first four cases nasal endoscopy showed the inflated

Table 1 Grade of epiphora according to Munk and the results of saline irrigation preoperatively and at each follow up examination

\begin{tabular}{|c|c|c|c|c|c|c|c|c|c|c|c|}
\hline \multirow[b]{2}{*}{ No } & \multirow[b]{2}{*}{ Age } & \multirow[b]{2}{*}{ Sex } & \multirow{2}{*}{$\begin{array}{l}\text { Duration of } \\
\text { symptoms }\end{array}$} & \multicolumn{4}{|c|}{ Epiphora grade } & \multicolumn{3}{|c|}{ Saline irrigation } & \multirow[b]{2}{*}{ Remarks } \\
\hline & & & & Preop & 3 months & 6 months & 12 months & 3 months & 6 months & 12 months & \\
\hline 1 & 37 & $\mathrm{~F}$ & 13 & 4 & 0 & 0 & 0 & $\mathrm{O}$ & $\mathrm{O}$ & $\mathrm{O}$ & Lost tubes 2 weeks postop \\
\hline 2 & 57 & $\mathrm{~F}$ & 27 & 4 & 1 & 2 & 2 & $\mathrm{O}$ & $\mathrm{P}$ & $\mathrm{P}$ & Massive intrasaccal inflammation \\
\hline 3 & 61 & $\mathrm{~F}$ & 4 & 4 & 0 & 0 & 0 & $\mathrm{O}$ & $\mathrm{O}$ & $\mathrm{O}$ & \\
\hline 4 & 41 & $\mathrm{~F}$ & 23 & 3 & 0 & 0 & 0 & $\mathrm{O}$ & $\mathrm{O}$ & $\mathrm{O}$ & Er-YAG MT \\
\hline 5 & 72 & $\mathrm{~F}$ & 15 & 4 & 0 & 0 & 0 & $\mathrm{O}$ & $\mathrm{O}$ & $\mathrm{O}$ & Er-YAG MT \\
\hline 6 & 44 & $\mathrm{~F}$ & 20 & 3 & 1 & 1 & 1 & $\mathrm{O}$ & $\mathrm{O}$ & $\mathrm{O}$ & \\
\hline 7 & 71 & $\mathrm{~F}$ & 23 & 3 & 1 & 1 & 1 & $\mathrm{O}$ & $\mathrm{P}$ & $\mathrm{P}$ & \\
\hline 8 & 40 & M & 20 & 4 & 2 & 2 & 2 & $\mathrm{O}$ & $\mathrm{P}$ & $\mathrm{C}$ & Severe allergical reaction \\
\hline 9 & 61 & M & 15 & 3 & 0 & 3 & 1 & $\mathrm{O}$ & $\mathrm{C}$ & $\mathrm{O}$ & Lost tubes 1 week postop re op \\
\hline 10 & 42 & M & 26 & 4 & 1 & 1 & 1 & $\mathrm{O}$ & $\mathrm{P}$ & $\mathrm{P}$ & \\
\hline 11 & 56 & $\mathrm{~F}$ & 5 & 4 & 1 & 3 & 3 & $\mathrm{P}$ & $\mathrm{C}$ & $\mathrm{C}$ & DCR \\
\hline 12 & 59 & M & 3 & 3 & 1 & 2 & 1 & $\mathrm{P}$ & $\mathrm{P}$ & $\mathrm{O}$ & Re-op \\
\hline 13 & 59 & M & 29 & 4 & 1 & 2 & 1 & $\mathrm{P}$ & $\mathrm{P}$ & $\mathrm{P}$ & \\
\hline 14 & 55 & M & 17 & 4 & 0 & 1 & 1 & $\mathrm{O}$ & $\mathrm{O}$ & $\mathrm{O}$ & \\
\hline 15 & 59 & $\mathrm{~F}$ & 25 & 4 & 1 & 1 & 1 & $\mathrm{O}$ & $\mathrm{O}$ & $\mathrm{O}$ & Er-YAG MT \\
\hline 16 & 87 & $\mathrm{~F}$ & 15 & 4 & 1 & 0 & 0 & $\mathrm{O}$ & $\mathrm{O}$ & $\mathrm{O}$ & Er-YAG MT \\
\hline 17 & 60 & M & 8 & 3 & 1 & 1 & 1 & $\mathrm{P}$ & $\mathrm{P}$ & $\mathrm{P}$ & \\
\hline 18 & 73 & M & 23 & 3 & 1 & 1 & 0 & $\mathrm{O}$ & $\mathrm{O}$ & $\mathrm{O}$ & \\
\hline 19 & 74 & $\mathrm{~F}$ & 5 & 4 & 2 & 2 & $\sim$ & $\mathrm{O}$ & $\mathrm{C}$ & $\sim$ & DCR \\
\hline 20 & 36 & M & 4 & 3 & 1 & 1 & 1 & $\mathrm{O}$ & $\mathrm{P}$ & $\mathrm{P}$ & \\
\hline 21 & 29 & $\mathrm{~F}$ & 7 & 3 & 1 & 1 & 1 & $\mathrm{O}$ & $\mathrm{O}$ & $\mathrm{P}$ & \\
\hline 22 & 51 & $\mathrm{~F}$ & 8 & 3 & 0 & 0 & 1 & $\mathrm{O}$ & $\mathrm{O}$ & $\mathrm{O}$ & Lost tubes 3 weeks postop \\
\hline 23 & 37 & $\mathrm{~F}$ & 12 & 4 & 0 & 2 & 3 & $\mathrm{O}$ & $\mathrm{P}$ & $\mathrm{C}$ & DCR \\
\hline 24 & 43 & M & 6 & 4 & 3 & $\sim$ & $\sim$ & $\mathrm{C}$ & $\sim$ & $\sim$ & DCR \\
\hline 25 & 60 & $\mathrm{~F}$ & 7 & 3 & 1 & 1 & 1 & $\mathrm{O}$ & $\mathrm{P}$ & $\mathrm{P}$ & \\
\hline 26 & 36 & $\mathrm{~F}$ & 4 & 3 & 0 & 0 & 0 & $\mathrm{O}$ & $\mathrm{O}$ & $\mathrm{O}$ & \\
\hline 27 & 55 & $\mathrm{~F}$ & 13 & 4 & 0 & 1 & 1 & $\mathrm{O}$ & $\mathrm{O}$ & $\mathrm{O}$ & \\
\hline 28 & 72 & M & 7 & 4 & 0 & 0 & 1 & $\mathrm{O}$ & $\mathrm{O}$ & $\mathrm{O}$ & \\
\hline 29 & 66 & $\mathrm{~F}$ & 10 & 3 & 1 & 1 & 0 & $\mathrm{O}$ & $\mathrm{P}$ & $P$ & \\
\hline 30 & 44 & $\mathrm{~F}$ & 14 & 3 & 1 & 1 & 1 & $\mathrm{O}$ & $P$ & $P$ & \\
\hline
\end{tabular}

$\mathrm{O}=$ open, $\mathrm{P}=$ partially closed, $\mathrm{C}=$ closed, Er-YAG $\mathrm{MT}=$ laser membranotomy. 
balloon just reaching the nasal cavity (Fig 2). The stiff catheter could not be moved after inflation indicating the appropriate placing at the stenotic area. It was then deflated and placed at the lower mark of the catheter at the superior punctum. The balloon was inflated again at 9 bar for 60 seconds, and was then completely deflated and pulled out of the superior canaliculus. Immediate irrigation after dilatation demonstrated free passage into the nose. Endoscopic control after dilatation provided evidence of the reopened passage (Fig 3).

For splinting the system a silicone intubation was performed immediately after dilatation. The entire procedure required about 15-20 minutes.

Antibiotic (Nebacetin, neomycin + bacitracin) and steroid (Ultracortenol, prednisolone) drops were instilled into the system. The patients were instructed to use both drops for 2 weeks four times daily.

The silicone tubes were removed between 3 and 6 months postoperatively.

Follow up examinations were performed 1 week, 1 month, 3 months, and then every 3 months postoperatively. At each follow up, Munk's grade was determined, irrigation was performed, and complications were entered in a database.

\section{Results}

In all cases balloon dilatation could be performed after opening the obstruction and gaining access to the nose through the nasolacrimal duct. In five cases $(16.6 \%)$ moderate bleeding occurred during the procedure; in all other cases only slight bleeding occurred and could be controlled by means of gentle pressure on the lids. In all cases a silicone intubation was performed immediately after dilatation. In six cases $(20.0 \%)$ only a monocanalicular intubation could be performed because of canalicular or communis stenosis. No

Preoperative

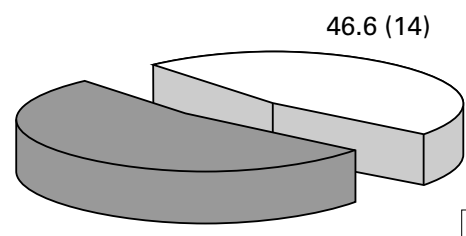

$53.3(16)$

Munk 3

Munk 4

6 months

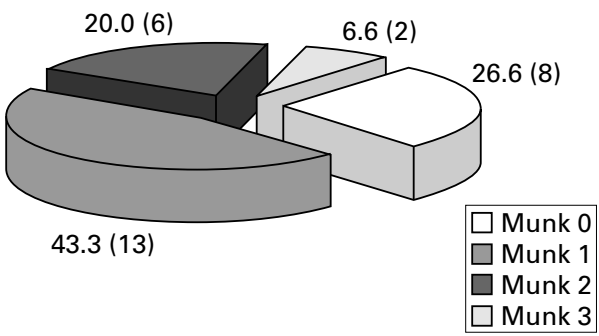

particular disadvantage due to local anaesthesia was observed. Several patients presented a blood tinged skin as a result of local anaesthesia and bloody nasal discharge for 1-3 days after the procedure The most uncomfortable sensation was experienced when the tubes were pulled through the nose by means of a tiny blunt hook. In three cases $(10.0 \%)$ the tubes were lost before the planned removal. In all other cases the tubes were removed 3 months postoperatively except for cases with Munk's grade 2 epiphora. In these cases tubes were removed after 6 months. The procedure was considered successful when epiphora had been completely eliminated or had been reduced to Munk's grade 1 .

Three months after the procedure saline irrigation revealed complete free passage in 27 obstructions (90.0\%). Eleven cases $(36.6 \%)$ had grade 0 tearing and 16 cases (53.3\%), grade 1 tearing. In three cases (patient nos 8, $19,24)(10.0 \%)$ the grade of epiphora was 2 or 3.

Six month results were available in 29 cases. Twenty one cases revealed free passage after irrigation (70\%) with Munk's classification 0 or 1 (eight, grade $0 ; 13$, grade 1 ). Eight cases $(26.6 \%)$ had Munk's grade 2 or grade 3 epiphora. One patient (no 24) required a conventional DCR to cure the postsaccal obstruction.

In one patient with a history of allergy the obstruction showed subjective improvement but did not meet the criteria for success (patient no 8). Two cases showed grade 3 epiphora. One patient lost the tubes 1 week after surgery and in one patient no particular cause could be found. In two patients (patient nos 9 and 12) a further dilatation was performed with consecutive silicone intubation and one additional patient (patient no 19) required a DCR after the 6 month follow up.

All cases (including those requiring redilatation) could be followed up for 1 year. In 25

3 months

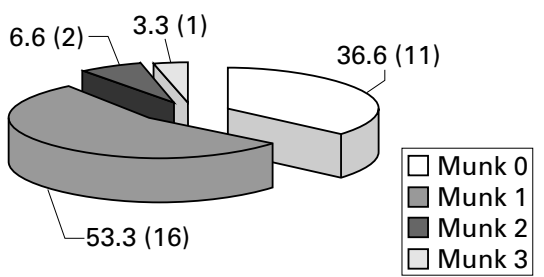

12 months

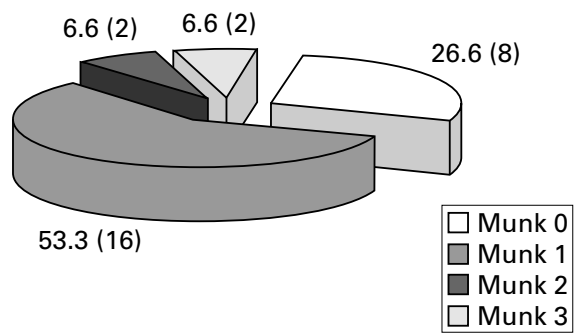

Figure 4 Preoperative and postoperative Munk's classification in numbers and percentages of procedures. 


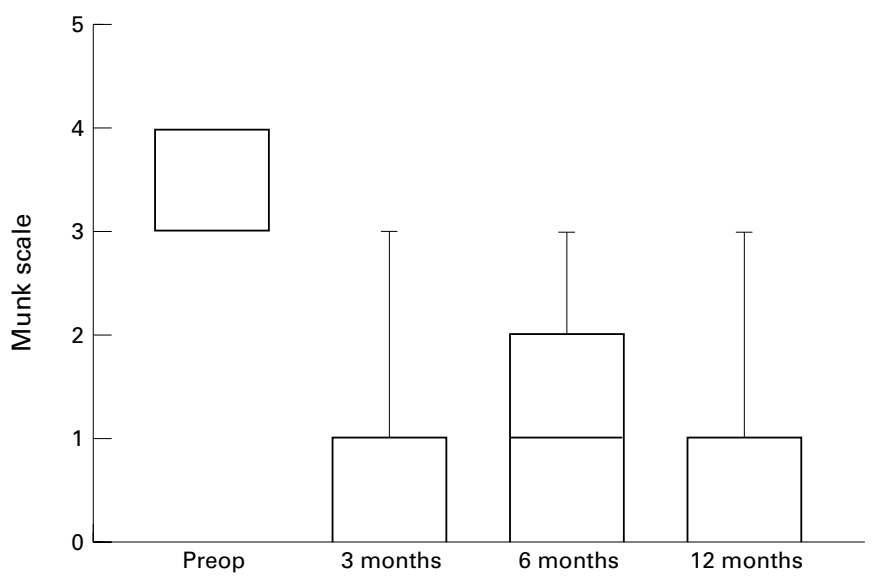

\begin{tabular}{|l|cccc|}
\hline \multicolumn{1}{|c|}{ X Labels } & Preop & 3 months & 6 months & 12 months \\
\hline Minimum & 3.000 & 0.0 & 0.0 & 0.0 \\
25\% Percentile & 3.000 & 0.0 & 0.0 & 0.0 \\
Median & 4.000 & 1.000 & 1.000 & 1.000 \\
75\% Percentile & 4.000 & 1.000 & 2.000 & 1.000 \\
Maximum & 4.000 & 3.000 & 3.000 & 3.000 \\
\hline
\end{tabular}

Figure 5 The course of the mean preoperative Munk's value compared with follow up examinations 3, 6, and 12 months postoperatively.

cases irrigation was successful after primary dilatation, although partial obstruction was observed in 10 cases. Eight cases $(26.6 \%)$ showed no epiphora and 16 cases $(53.3 \%)$ had grade 1 epiphora, which amounted to a success rate of $79.9 \%$. Two patients had grade 2 epiphora and two patients grade 3 epiphora. In the latter patients (patient nos 11 and 23) a conventional DCR had been performed after 1 year. Even excluding the successfully repeated dilatation in two cases the rate of success after primary treatment was as high as $73.3 \%$ after 1 year. In two patients a repeated dilatation was performed successfully and four patients required a DCR to cure persistent or recurrent epiphora between 4 and 12 months after dilatation (Table 1).

The results are graphically detailed in Figures 4 and 5. In Figure 5 data are drawn graphically by box whisker plots indicating a reduction from grade 4 to grade 1 at the $75 \%$ percentile at the 1 year follow up.

\section{Discussion}

Most cases of acquired nasolacrimal duct obstruction in adults result from age related stenotic changes in the lacrimal drainage system. Stenosis may predispose the sac to stasis and infection, which causes pathological changes in the lacrimal mucous membrane. ${ }^{26-28}$ Balloon catheter dilatation may reopen a pathological obstruction and can lead to recanalisation of the lacrimal drainage system.

Several published reports describe retrograde dilatation requiring radiographic support. ${ }^{13-21}$ These procedures are very expensive, because of the radiological equipment, and time consuming. The long term success rates are reported to range between $90 \%$ and $25 \% .^{16} 17$ Our own results of retrograde dilatation combined with monocanalicular silicone intubation demonstrated a success rate of $60 \%$ in partial obstructed nasolacrimal ducts. ${ }^{18}$ In most of the previous reports no silicone intubation was performed and a higher rate of recurrent epiphora was registered. Consecutive silicone intubation for splinting the reopened stenosis seems to be very important for permanent patency during the initial scarring process.

Munk and others ${ }^{13}$ consider substantial improvement to consist of reduction of epiphora to grade 1 or grade 0 . Accordingly, we used a reduction of epiphora to grade 1 or grade 0 as the criterion for subjective success. Three months after dilatation a positive irrigation could be achieved in $90.0 \%$. A significant reduction of epiphora according to Munk's scale was regarded as evidence of a patent nasolacrimal duct. The 1 year success rate of $79.9 \%$ is high enough to warrant performance of this procedure as primary surgery in all cases with postsaccal stenosis except in patients with a history of severe allergy, lacrimal sac tumours, former lacrimal surgery, or traumatic changes in the lacrimal bone. Perry and others reported similar results in patients with partial stenosis using antegrade dilatation. ${ }^{23}$ As reported in the latter paper we also performed silicone intubation in every case. Compared with previous reports of silicone intubation alone for lacrimal pathway obstruction reporting success rates of $22 \%-78 \%$, an additional dilatation in completely obstructed postsaccal passages may improve the rate of success. Postoperative endoscopic control of the lacrimal pathway system demonstrated recanalisation and showed the silicone tubes to be in place in all cases. The silicone tubes were removed after 3 months, thus avoiding possible complications of long term silicone intubation. ${ }^{27}$

No difference was observed between patients with long standing obstructions and those suffering from epiphora of a few months' duration. Patients with a history of allergy did not meet our criterion of success in spite of silicone intubation and local steroid medication. Those patients are not suitable candidates for primary dilatation. In all other cases balloon catheter recanalisation may be an effective primary treatment. The fact that it can be performed under local anaesthesia makes it even more suitable.

Most recurrences of epiphora occurred during the first 6 months after treatment. Owing to persistent epiphora in spite of silicone intubation, four patients required a DCR between 4 and 12 months after initial dilatation. Endoscopy showed intrasaccal and postsaccal stenosis, which could not be reopened successfully by dilatation. A further two patients lost their tubes and needed a repeated dilatation procedure within 6 months. Thus, in six cases $(20.0 \%)$ primary dilatation failed and further surgery was required to cure epiphora.

Antegrade dilatation is a procedure which can be performed on an outpatient basis under local anaesthesia. The entire procedure, including silicone intubation, requires no more than 15-20 minutes. Expensive equipment as in retrograde dilatation is not needed. The procedure can be performed easily, is repeatable and avoids an external approach through the skin 
and bone. Therefore, it is best suited as an initial approach in patients with acquired postsaccal stenosis except traumatic cases, lacrimal sac tumours, and patients with severe allergy.

In spite of encouraging 1 year results long term observations will be required to prove the efficacy of the procedure over several years.

1 Rosen N, Sharir M, Moverman D, et al. Dacryocystorhinostomy with silicone tubes: evaluation of 253 cases. Ophthal tomy with silicone tubes:
mic Surg 1989;20:115-19.

2 Zolli CL, Shannon GM. Dacryocystorhinostomy: a review of 119 cases. Ophthalmic Surg 1982;13:905-10.

3 Soll DB. Silicone intubation: an alternative to dacryocystorhinostomy. Trans Am Acad Ophthalmol Otolaryngol $1978 ; 85: 1259-65$.

4 Angrist RC, Dortzbach RK. Silicone intubation for partial and total nasolacrimal duct obstruction in adults. Ophthalmic Plast Reconstr Surg 1985;1:51-4.

5 Psilas K, Eftaxias V, Kastanioudakis J, et al. Silicone intubation as an alternative to dacryocystorhinostomy for nasolacrimal drainage obstruction in adults. Eur f Ophthalmol 1993;3:71-6.

6 Massaro BM, Gonnering RS, Harris GJ. Endonasal laser dacryocystorhinostomy: a new approach to nasolacrimal duct obstruction. Arch Ophthalmol 1990;108:1172-6.

7 Gonnering RS, Lyon DB, Fisher JC. Endoscopic laserassisted lacrimal surgery. Am f Ophthalmol 1991;111:152-7.

8 Christenburry JD. Translacrimal laser dacryocystorhinostomy. Arch Ophthalmol 1992;110:170-1.

9 Levin PS, Stormogipson DJ. Endocanalicular laser-assisted dacryocystorhinostomy: an anatomic study. Arch Ophthalmol 1992;110:1488-90.

10 Silkiss RZ, Axelrod RN, Iwach AG, et al. Transcanalicular THC:YAG dacryocystorhinostomy. Ophthalmic Surg 1992 23:351-3

11 Kuchar A, Novak P, Fink M, et al. The use of a diode laser for antegrade laser dacryocystorhinostomy. Orbit 1997; 16(Suppl):59-65.

12 Kuchar A. Endoscopic laser recanalisation of presaccal canalicular obstruction. Br f Ophthalmol 1999;83:443-7.

13 Munk PL, Lin DT, Morris DC. Epiphora: treatment by means of dacryocystoplasty with balloon dilation of the nasolacrimal drainage apparatus. Radiology 1990;177:68790.
14 Robinson R, Turner N, Brettle P, et al. The treatment of epiphora with balloon dacryocystoplasty. Eye 1993;7:687-

15 Song HY, Ahn HS, Park CK, et al. Complete obstruction of the nasolacrimal system. Radiology 1993;186:367-71.

16 Lee JM, Song HM, Han YM, et al. Balloon dacryocystoplasty: results in the treatment of complete and partial obstructions of the nasolacrimal system. Radiology 1994;192:503-8.

17 Janssen AG, Mansour K, Krabbe GJ, et al. Dacryocystoplasty: treatment of epiphora by means of balloon dilation of the obstructed nasolacrimal duct system. Radiology 1994;193:453-6.

18 Steinkogler FJ, Huber E, Kuchar A, et al. Retrograde dilation of postsaccal lacrimal stenosis. Ann Otol Rhinol Laryngol 1994;103:110-14.

19 Kumar EN. Technical note: non-surgical treatment of epiphora by balloon dacryocystoplasty-the technique. $\mathrm{Br}$ f Radiol 1995;68:1116-18.

20 Liermann D, Berkefeld J, Fries U, et al. Balloon dacryoplasty:an alternative treatment for obstructed tear ducts. Ophthalmologica 1996;210:319-24.

21 Hermeking H, Podder M, Gerke E, et al. Lacrimal duct recanalization with balloon catheter. Der Ophthalmologe 1997:45-9.

22 Yazici Z, Yazici B Parlak M, et al. Treatment of obstructive epiphora in adults by balloon dacryocystoplasty. $\mathrm{Br} \mathcal{F} \mathrm{Oph}$ thalmol 1999;83:692-6.

23 Perry JD, Maus M, Nowinski TS, et al. Balloon catheter dilation for treatment of adults with partial nasolacrimal duct obstruction: a preliminary report. Am f Ophthalmol 1998;126:811-16

24 Murdoch IE, Morris SS, Cousens SN. People and eyes: statistical approaches in ophthalmology. $\mathrm{Br} \mathcal{F}$ Ophthalmol 1998;82:971-3.

25 Newcombe RG, Duff GR. Eyes or patients? Traps for the unwary in the statistical analysis of ophthalmological studies. Br f Ophthalmol 1987;71:645-6.

26 Spencer WH. Ophthalmic pathology: an atlas and textbook. Philadelphia: WB Saunders, 1996.

27 Linberg JV, McCormick SA. Primary acquired nasolacrimal duct obstruction: a clinicopathological report and biopsy technique. Ophthalmology 1986;93:1055-63.

28 Steinkogler FJ. The postsaccal, idiopathic dacryostenosisexperimental and clinical aspects. Doc Ophthalmol 1986;63: $265-8$. 